\title{
Evolution of mylonitic microfabrics (EMM), a computer application for educational purposes
}

\author{
Marco Herwegh $^{\mathrm{a}, *}$, Mark R. Handy ${ }^{\mathrm{b}}$, Renée Heilbronner $^{\mathrm{c}}$ \\ ${ }^{a}$ Geological Institute, University of Bern, 3012 Bern, Switzerland \\ ${ }^{b}$ Institute of Geosciences, Justus Liebig University, Giessen, Germany \\ ${ }^{c}$ Geological and Paleontological Institute, University of Basel, Basel, Switzerland
}

Accepted 30 October 1998

\begin{abstract}
'Evolution of mylonitic microfabrics' (EMM) is an interactive Filemaker Pro 3.0 application that documents a series of see-through deformation experiments on polycrystalline norcamphor. The application comprises computer animations, graphics and text explanations designed to give students and researchers insight into the interaction and dynamic nature of small-scale, mylonitic processes like intracrystalline glide, dynamic recrystallization and strain localization (microshearing). EMM shows how mylonitic steady state is achieved at different strain rates and temperatures. First, rotational mechanisms like glide-induced vorticity, subgrain rotation recrystallization and rigid-body rotation bring grains' crystal lattices into orientations that are favorable for intracrystalline glide. In a second stage, selective elimination of grains whose lattices are poorly oriented for glide involves grain boundary migration. This strengthens the texture. Temperature and strain rate affect both the relative activity of different strain accommodation mechanisms and the rate of microfabric change. Steady-state microfabrics are characterized by stable texture, grain size and shape-preferred orientations of grains and domains. This involves the cyclical generation and elimination of dynamically recrystallized grains and microshear zones. (C) 1999 Elsevier Science B.V. All rights reserved.
\end{abstract}

Keywords: norcamphor; rock analogue experiments; dynamic recrystallization; steady state

\section{Introduction}

Microfabrics provide information about the physical conditions, kinematics and processes of deformation. One way to gain a better understanding of microfabric evolution is to deform rock analogue materials in see-through deformation apparatuses. Beginning with the pioneering work of Wakahama (1964) and Means (1977), this approach has become increas-

\footnotetext{
* Corresponding author. Tel.: +41-31-631-8764; Fax: +41-31-
} 631-4843; E-mail: herwegh@geo.unibe.ch ingly popular over the past two decades as a way of studying microstructural processes. Experimentalists have employed many rock analogue materials (e.g. Urai and Humphreys, 1981; Means, 1989; Bons, 1993; Means and Park, 1994) and the increasing sophistication of computer soft- and hardware (Jessell, 1986; Bons, 1993; Bons et al., 1993; Park, 1994) as well as of technical equipment (e.g. Urai, 1983; Jessell and Lister, 1991; Bons, 1993) have increased the quantity and quality of information. Very instructive teaching material resulted from these experiments, which helped to understand mi- 
crofabric evolution during deformation. Wilson and Burg (1986), for example, produced a fascinating video on the deformation and dynamic recrystallization of ice (see also Burg et al., 1986). Mark Jessell and Paul Bons now offer a microstructure course on the internet (http://www.earth.monash.edu.au/mark/ mscourse/intro.html) in which computer animations of numerically modelled texture evolution help students to understand the physical concepts associated with the deformation of geological materials.

Following on a series of simple shear experiments on norcamphor as an analogue material for mylonitic quartz (Herwegh and Handy, 1996), we have recently applied the new method of computer-integrated polarization microscopy (CIP, see Panozzo Heilbronner and Pauli, 1993) to document all aspects of microstructure development in seethrough experiments (Herwegh et al., 1997). The CIP method allowed us to calculate the position of norcamphor $c$-axes for each individual image pixel and to attribute a specific color to it. With this technique we derived detailed, digital $c$-axis orientation images (COI, see also Heilbronner and Herwegh, 1997) of entire grain aggregates during the deformational experiments. By combining this approach with (1) strain analysis (marker analysis, Bons et al., 1993) and (2) grain/domain shape analysis (SURFOR, Panozzo, 1983; PAROR, Panozzo, 1984), we were able to characterize the texture and microstructural parameters (i.e. shape-preferred orientations, grain size and strain distribution). The evolution and changes of these parameters allowed us to infer the strain accommodation mechanisms during progressive deformation.

Although we have published the results of our study in various journals (see citations above and reference list), hard copy publications unfortunately cannot provide readers with a movie that satisfactorily documents the dynamic nature of microfabric evolution. It is to this end that we have created 'Evolution of Mylonitic Microfabrics' (EMM). It is a publicly available computer package that contains movies, illustrations and explanations of the see-through experiments published in Herwegh and Handy (1996), Herwegh et al. (1997) and Herwegh and Handy (1998). Below, we briefly specify the computer requirements for EMM and outline the essential contents and advantages of the application.

\section{Computer requirements}

EMM uses Filemaker Pro 3.0 from Claris $^{\mathrm{TM}}$. To use EMM, one needs a Macintosh computer with at least $8 \mathrm{Mb}$ RAM. Power Macs augment the animation speed of the numerous QuickTime ${ }^{\mathrm{TM}}$ sequences within the application. EMM itself requires a storage space of about $30 \mathrm{Mb}$.

\section{Content of EMM}

EMM comprises several page stacks with Quick Time animations, graphics and text explanations. EMM is easy to handle. Using the mouse to click onto the screen buttons, one can either activate animations or move between the individual chapters, subchapters and pages. The application is divided into three parts (Introduction, Experiments, and Microfabric Evolution, Fig. 1) described below. Note that the computer application only visualizes what we observed in our experiments and does not animate a numerical model.

\subsection{Part 1: Introduction}

The main goal of EMM is to visualize the relationship of microstructure and texture during progressive deformation. This, as well as information about the techniques applied and the contents of the application, is presented in the introductory chapter. Overview Fig. 1 lists the different levels of the program and the paths for reaching these levels. Clicking a glossary button on each page yields definitions of special terms used in EMM.

\subsection{Part 2: Experiments}

This chapter contains information about norcamphor as a rock analogue material, the experimental configuration, the experimental conditions and the microfabrics formed during the experiments (Fig. 1). It documents four series of norcamphor experiments at different strain rate and temperature conditions: high temperature-low strain rate (HT-LS), high temperature-high strain rate (HT-HS), intermediate temperature-high strain rate (IT-HS) and low temperature-high strain rate (LT-HS). The micro- 


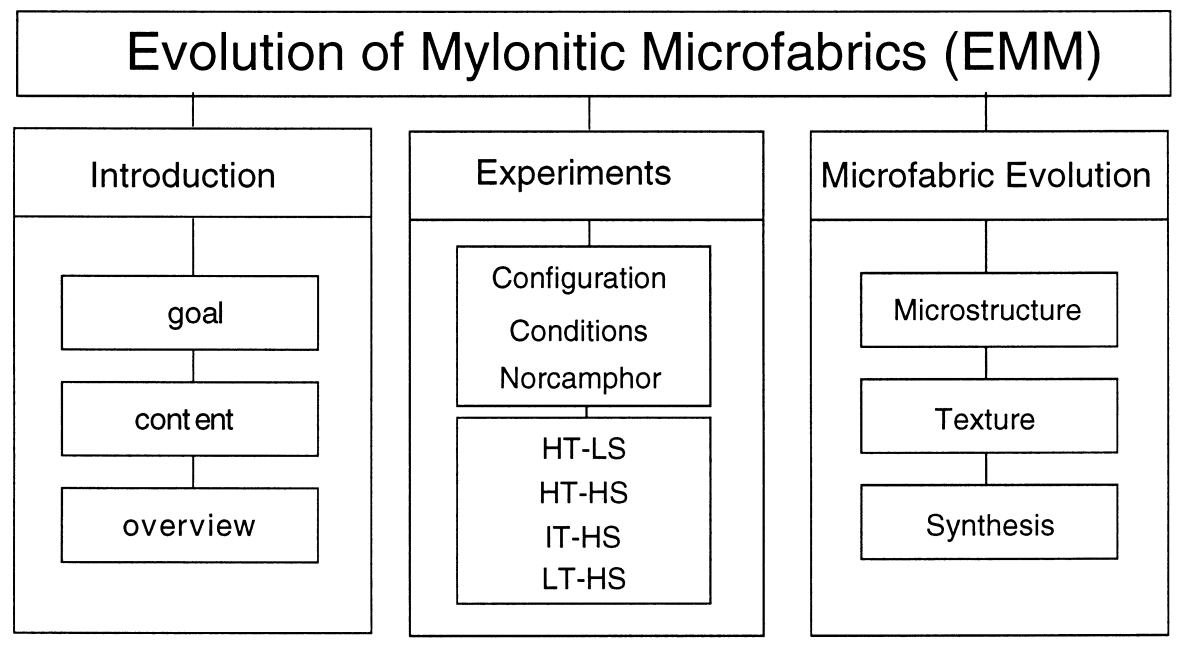

Fig. 1. Schematic overview of the levels in EMM.

fabrics produced during these experiments are very similar to those of quartz in greenschist to amphibolite facies quartz mylonites. The evolution of norcamphor microfabric (Fig. 2a), grain size, texture (Fig. 2b) and the strain distribution are visualized for each experiment with Quick Time movies. Additional diagrams characterize strain-dependent changes in mechanism activities, area proportions of crystallographic domains (Fig. 3) and shape-preferred orientations of grains and domains.

\subsection{Part 3: Microfabric evolution}

This part of EMM comprises a discussion of the experimental results on textural and microstructural evolution and presents a model of microfabric evolution in monomineralic mylonite. The norcamphor microfabric passes through two transient stages before attaining steady state. The nature of these stages described below does not vary with the conditions (temperature, strain rate) of deformation. During the first transient stage, the crystallographic axes of individual grains rotate toward orientations that are favorable for easy intracrystalline gliding (i.e. easy glide orientations) and a strong texture develops (Fig. 2, first row). The increase in areal proportion of bright grains in Fig. 3 shows that grains with a new crystallographic orientation grow at the expense of other, less favorable orientations. The rotation rate of grains' $c$-axes is high at the beginning of the first transient stage but decreases to low values near the transition to the second stage. Considered in the context of the bulk texture, $c$-axes in orientations with a low rotation rate define a cross-girdle that is symmetrically disposed with respect to the long axis of the finite strain ellipse. In aggregates undergoing simple shearing, this texture is interpreted to manifest two-dimensional pure shear extension parallel to the incremental stretching direction. The relative activity of the rotational mechanisms (i.e. glide-induced vorticity, subgrain rotation recrystallization and rigid-body rotation) varies with strain and is also closely linked to the strain rate and temperature of the experiment. In the case of the HTLS experiments, for example, glide-induced vorticity is the major rotational mechanism, whereas at ITHS conditions subgrain rotation recrystallization predominates. This results in a reduction of the average grain size. In all experiments, however, rotational mechanisms are accompanied by grain boundary migration recrystallization. This eliminates grains with crystallographic orientations that are less favorable for easy intracrystalline gliding. In the low-temperature experiments, intracrystalline plasticity is unable to maintain strain compatibility, leading to fracturing as an additional strain accommodation mechanism.

During the second transient stage of microfabric development, continuously low $c$-axis rotation rates reflect the reduced activity of the rotational mechanisms. At the same time, the areal proportion 

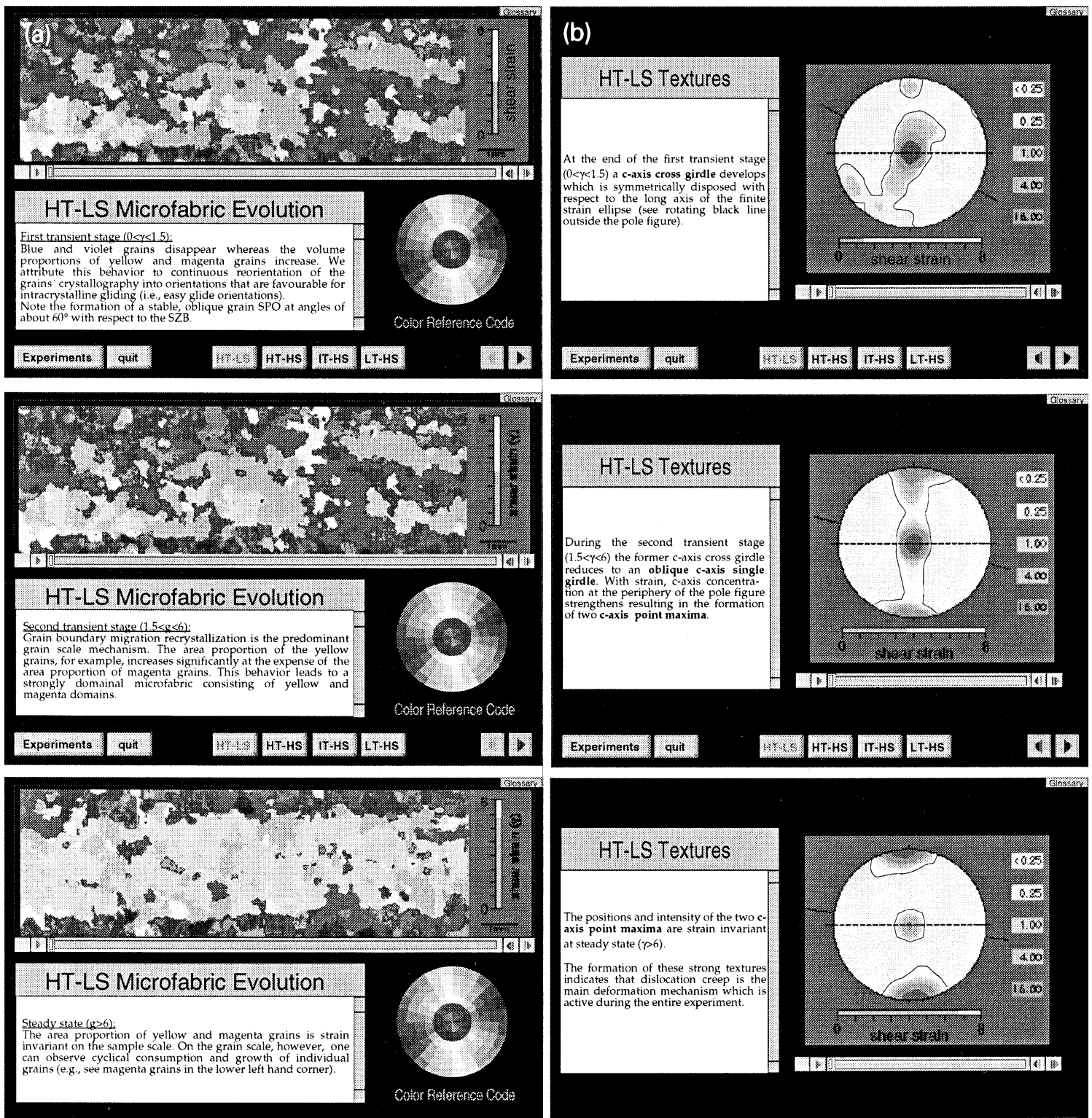

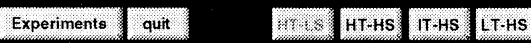
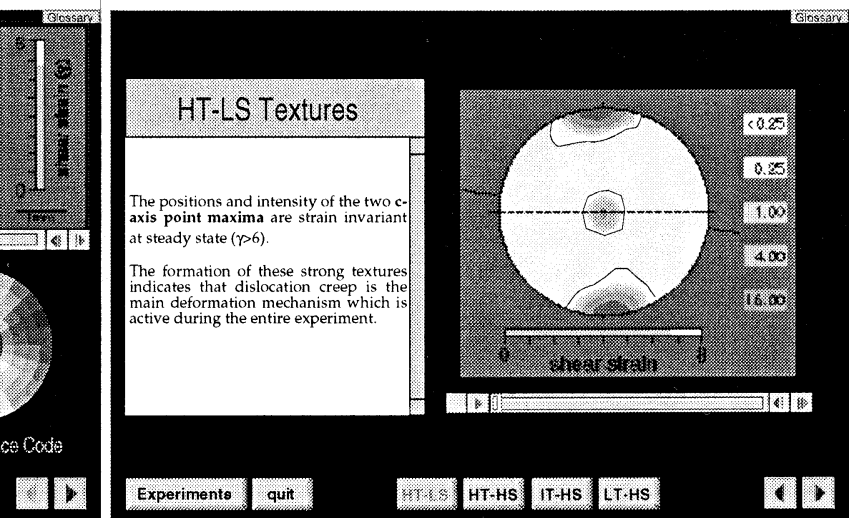

Fig. 2. During progressive deformation the norcamphor microfabric evolves through two transient stages (first and second row) before attaining steady state (third row). Column (a) shows the CIP-generated images of the microfabric evolution. Note that the gray values of the grain aggregates are attributed to specific $c$-axis orientations which can be inferred directly by using the gray value reference pole figure. Column (b) summarizes the textural evolution. See text for explanation.

of grains with favorable glide orientations increases very rapidly due to the increased activity of grain boundary migration recrystallization (Fig. 3). The dynamically recrystallized grain size increases drastically in the high-temperature experiments. This selective elimination of unfavorably oriented grains is directly related to reduction of the $c$-axis crossgirdle pattern to a $c$-axis single-girdle pattern. The rate at which the areal proportions of the different crystallographic orientations changes is high for 


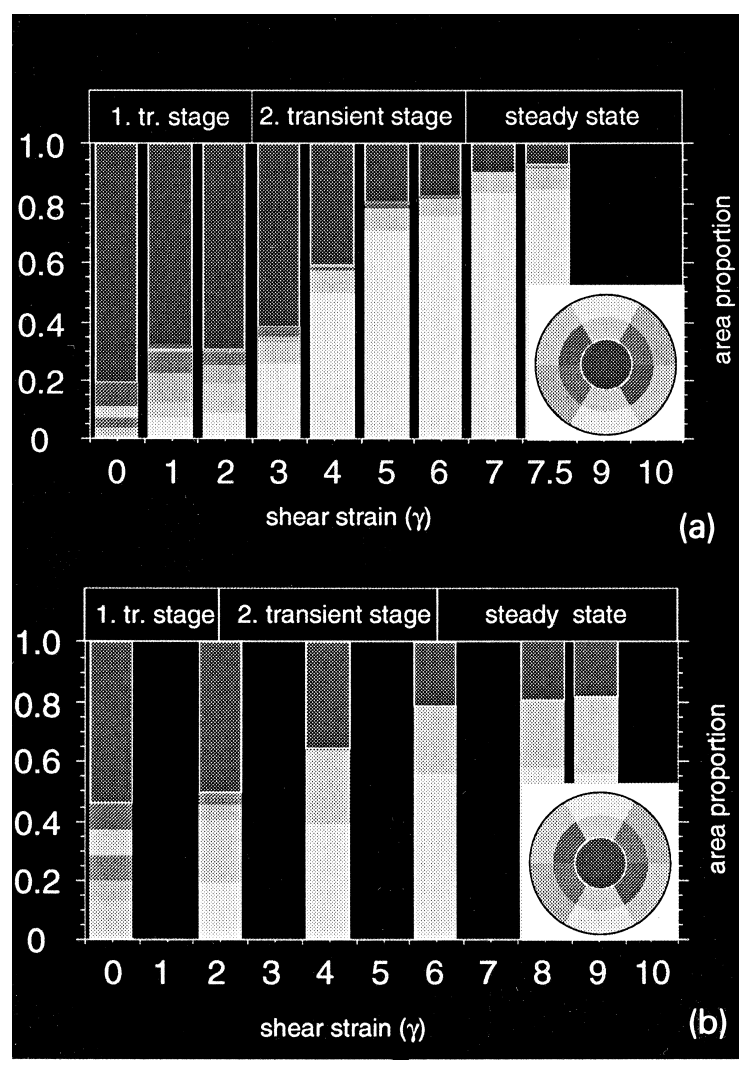

Fig. 3. Diagrams show the changes in areal proportion of the different crystallographic orientations for both HT-LS (a) and IT-HS experiments (b). The gray value reference code for the different $c$-axis orientations is given in the lower right-hand corner.

high-temperature experiments (i.e. HT-LS and HTHS) and low for the intermediate- to low-temperature experiments. This merely reflects that grain boundary migration recrystallization selects for favorably oriented grains more efficiently at higher temperatures and/or lower strain rates.

During both transient stages of microfabric development, strain localization on the intergranular scale leads to the formation of microshears which control the grain-shape-preferred orientation (SPO) of the microstructure (see Herwegh and Handy, 1998). Microshears initiate at high angles to the shear zone boundaries and rotate synthetically. At angles of $60^{\circ}$ and $10-20^{\circ}$ with respect to the shear zone boundary, the microshears accommodate large local strains per increment of bulk shear strain. This leads to the development of a domainal microfabric in which the steep $\mathrm{Sb}$ microshears define the grain SPO, whereas the weakly inclined $\mathrm{Sa}$ microshears delineate the domain boundaries.

The evolution and preservation of a steady-state microfabric involves a combination of intracrystalline glide, subgrain rotation, grain boundary migration and intragranular microshearing. The experiments show that different microfabric features attain steady state at different shear strains and on different scales: on the sample scale, texture, grain size, and SPO are strain-invariant at shear strains greater than 6. It is important to note that even at high shear strains the $c$-axis of individual grains rotate at low rates and therefore are not stable on the granular scale. Thus, glide systems not only rotate into easy glide orientations with high critical resolved shear stresses, they also rotate out of them (Herwegh et al., 1997, controversy discussed by Wenk and Christie, 1991 and by Schmid, 1994). However, grains with glide planes that rotate out of an easy glide orientation are soon consumed by grains with lattices more favorably oriented for easy intracrystalline gliding. This cyclic rotation and consumption of individual grains preserves a stable steady-state, bulk texture. On the intergranular scale, the generation, rotation and deactivation of microshears maintains a stable grain and domain SPO. In sum, the cyclicity of strain accommodation mechanisms on the granular and interganular scale reflects the highly dynamic, heterogeneous nature of steady state.

\section{Advantages of EMM}

EMM provides students with vivid images of the way in which mylonites evolve. It therefore compliments microscopic studies of rock thin-sections, which usually preserve the final stages of a long deformational history. EMM can be used by individual students on personal computers or presented to a group of students with modern projection methods (e.g. overhead projections with liquid crystal displays). EMM is provided free of charge. Please send either a $100 \mathrm{Mb}$ ZIP cartridge to the first author (M. Herwegh) and enclose 10 US\$ to cover packaging and mailing costs. Recently, EMM is also available on the internet (http://www.earthsci.unibe.ch/people/ herwegh/emm.html). 


\section{Acknowledgements}

We gratefully acknowledge the reviews of $\mathrm{M}$. Jessell and J. Urai and financial support of the Swiss National Science Foundation (grants 21-30598.91, 21-33814.92 and 21-36008.92).

\section{References}

Bons, P.D., 1993. Experimental deformation of polyphase rock analogues. Geol. Ultrajectina 110, 207 pp.

Bons, P.D., Jessell, M.W., Passchier, C.W., 1993. The analysis of progressive deformation in rock analogues. J. Struct. Geol. 15, 403-412.

Burg, J.P., Wilson, C.J.L., Mitchell, J.C., 1986. Dynamic recrystallization and fabric development during simple shear deformation of ice. J. Struct. Geol. 8, 857-870.

Heilbronner, R., Herwegh, M., 1997. Time slicing, an image processing technique to visualize the temporal development of fabrics. J. Struct. Geol. 19, 861-874.

Herwegh, M., Handy, M.R., 1996. The evolution of high temperature mylonitic microfabrics: evidence from simple shearing of a quartz analogue (norcamphor). J. Struct. Geol. 18, 689710 .

Herwegh, M., Handy, M.R., 1998. The origin of shape preferred orientations in mylonite: inferences from in-situ experiments on polycrystalline norcamphor. J. Struct. Geol. 20, 681-694.

Herwegh, M., Handy, M.R., Panozzo-Heilbronner, R., 1997. Temperature and strain rate dependent microfabric evolution in monomineralic mylonite: evidence from in situ deformation of a rock analogue. Tectonophysics 280, 83-106.

Jessell, M.W., 1986. Grain boundary migration and fabric development in experimentally deformed octachlorapropane. J. Struct. Geol. 8, 527-542.

Jessell, M.W., Lister, G.S., 1991. Strain localization behavior in experimental shear zones. Pure Appl. Geophys. 137, 421-438.
Means, W.D., 1977. A deformation experiment in transmitted light. Earth Planet. Sci. Lett. 35, 169-179.

Means, W.D., 1989. Synkinematic microscopy of transparent polycrystals. J. Struct. Geol. 11, 163-174.

Means, W.D., Park, Y., 1994. New experimental approach to understanding igneous texture. Geology 22, 323-326.

Panozzo, R., 1983. Two-dimensional analysis of shape-fabric using projections of digitized lines in a plane. Tectonophysics 95, 249-279.

Panozzo, R., 1984. Two-dimensional strain from the orientation of lines in a plane. J. Struct. Geol. 6, 215-221.

Panozzo Heilbronner, R., Pauli, C., 1993. Integrated spatial and orientation analysis of quartz c-axes by computer-aided microscopy. J. Struct. Geol. 15, 369-383.

Park, Y., 1994. Microstructural Evolution in Crystal-Melt Systems. PhD Thesis, State University of New York at Albany (unpublished).

Schmid, S.M., 1994. Textures of geological materials: computer model predictions versus empirical interpretations based on rock deformation experiments and field studies. In: Bunge, H.J., Siegesmund, S., Skrotzki, W., Weber, K. (Eds.), Textures of Geological Materials. DGM Informationsgesellschaft-Verlag, Oberursel, pp. 279-301.

Urai, J.L., 1983. Deformation of Wet Salt Rocks: an Investigation into the Interaction between Mechanical Properties and Microstructural Processes during Deformation of Polycrystalline Carnallite and Bischofite in the Presence of a Pore Fluid. PhD. Thesis, Utrecht University, 223 pp.

Urai, J.L., Humphreys, J.F., 1981. The development of shear zones in polycrystalline camphor. Tectonophysics 78, 677685 .

Wakahama, G., 1964. On the plastic deformation of ice. Low Temperature Sci. 22, 1-24.

Wenk, H.-R., Christie, J.M., 1991. Comments on the interpretation of deformation textures in rocks. J. Struct. Geol. 13, 1091-1110.

Wilson, C.J.L., Burg, J.P., 1986. Dynamic processes in the shear of ice as a rock analogue. Video tape. The University of Melbourne, Parkville, VIC 3052 